\title{
К ВОПРОСУ О НЕКОТОРЫХ ТЕНДЕНЦИЯХ РАЗВИТИЯ ИНСТИТУТА АУДИТА (ОРГАНИЗАЦИОННО-ПРАВОВЫЕ АСПЕКТЫ И СТРАТЕГИЧЕСКИЙ АУДИТ)
}

\author{
(C) 2019 Терехова Елена Владиславовна \\ кандидат юридических наук \\ Российский государственный университет правосудия, Россия, Москва \\ E-mail: Ter_finlaw@mail.ru
}

Проанализированы тенденции в области развития института аудита, выявлены некоторые организационно-правовые проблемы и предложены пути их решения. В статье рассматриваются основные виды государственного аудита, а также предложен и обоснован процесс внедрения системного аудита.

Ключевые слова: государственный аудит, национальные приоритеты, стратегический аудит, аудит инвестиционных проектов, системный аудит.

В условиях меняющейся парадигмы финансовой дисциплины, развития технологической составляющей, а также влияния глобализации на процессы экономической деятельности в стране сигнализируют о необходимости поновому посмотреть на институт контроля, и в частности аудит.

На сегодняшний момент актуальной темой является экономическая безопасность в рамках обеспечения экономического суверенитета Российской Федерации, устойчивого развития экономики путем формирования института гарантий, мер защиты, а также обеспечения конфиденциальности сведений финансовой и иной документации российских организаций.

При этом динамика в развитии государственного управления требует уточнения роли и функций органов аудита в государственном управлении. Целевой вектор аудита направлен на эффективное администрирование финансов, качество жизни граждан, реализацию подходов к решению глобальных и трансграничных проблем.

С учетом вышесказанного отметим, что ключевой задачей высших органов аудита является достижение национальных приоритетов и целей. Достижению заданной цели способствует проведение контрольных мероприятий в рамках системного аудита, а именно стратегического аудита.

Одним из основных векторов направлений контрольной и экспертно-аналитической деятельности Счетной палаты РФ в период с 2019 по 2021 год [1] является проведение стратегического аудита (в том числе проведение мероприятий в целях мониторинга и оценки достижения национальных целей, обозначенных в Указе Президента Российской Федерации от 7 мая 2018 г. N204 «O национальных целях и стратегических задачах развития Российской Федерации на период до 2024 года» [2] (далее - Указ от 7 мая 2018 г. N204). Программы контрольных мероприятий содержат оценку хода реализации национальных проектов и государственных программ Российской Федерации, а также оценку достаточности утвержденных проектов и программ для достижения национальных целей, выработке рекомендаций по расширению возможностей достижения показателей национальных проектов с учетом результатов стратегического аудита, аудита эффективности и финансового аудита (ключевых видов государственного аудита).

Все направления деятельности Счетной палаты РФ в плановом периоде будут использовать риск-ориентированный подход при планировании и проведении контрольных и экспертно-аналитических мероприятий с учетом лучших практик высших органов аудита иностранных государств и аудиторских организаций коммерческого сектора, что позволит повысить качество результирующих документов.

Следует отметить, что изменение направлений (векторов) видов государственного аудита влечет за собой соответственно и изменение работы (деятельности) Счетной палаты. Каждое направление деятельности при формировании плана работы Счетной палаты должно ориентироваться на формирование ожидаемого результата (тематики), который может оказать существенное влияние на экономическую ситуацию 
в стране или определенной отрасли, привлечь общественное внимание, а также содействовать принятию мер по устранению выявленных недостатков и нарушений.

В основу развития Счетной палаты РФ закладывается стратегическое управление, а также изменение ее внутренней системы, включая: внедрение полного цикла стратегического управления с учетом разработки и корректировки стратегии, измерение достижения стратегических целей, внедрение инициатив по реализации стратегии; внедрение системы проектного управления при решении нестандартных задач и реализации стратегических инициатив; внедрение системы показателей результативности деятельности контрольно-счетного органа.

Следует отметить, что результатами реализации основного направления контрольной и экспертно-аналитической деятельности Счетной палаты РФ в области стратегического аудита в трехлетнем периоде планируются: функционирование системы независимого и альтернативного мониторинга и оценки достижения национальных целей и реализации национальных проектов; рекомендации Правительству РФ и органам исполнительной власти по совершенствованию системы стратегического планирования и управления, включая управление рисками недостижения национальных целей, и устранению предпосылок к возникновению рисков; рекомендации по повышению качества документов стратегического планирования; разработка и апробация экспериментальных методов анализа при проведении проверочных мероприятий по актуальным проблемам государственного управления.

В рамках стратегического аудита осуществляется оценка результатов стратегических целей и задач обеспечения безопасности и социально-экономического развития Российской Федерации, а также рисков. Оценке подлежат конечные и достигнутые значения ключевых национальных показателей в разрезе регионов и федеральных округов.

Ключевыми объектами стратегического аудита являются документы стратегического планирования. В соответствии с Федеральным законом РФ от 28 июня 2014 г. № 172-Ф3 «О стратегическом планировании в Российской Федерации» [3] (ст. 11) такими документами, например, выступают стратегии социально-экономического развития макрорегионов, госу- дарственные программы Российской Федерации, схемы территориального планирования Российской Федерации и др.

Кроме того, объектами стратегического аудита могут выступать инвестиционные проекты, приоритетные инвестиционные проекты с государственным участием (финансированием).

На основании «СГА 304. Стандарт внешнего государственного аудита (контроля). Аудит государственных и международных инвестиционных проектов» (утв. постановлением Коллегии Счетной палаты РФ от 23.12.2016 N8ПК) [4] задачами аудита инвестиционных проектов являются: оценка соответствия целей инвестиционных проектов содержанию документов стратегического планирования, приоритетам и целям государственной политики в сфере социально-экономического развития и безопасности; оценка обоснованности объемов капитальных вложений (инвестиций), планируемых на различных стадиях реализации инвестиционных проектов; оценка обоснованности сроков осуществления капитальных вложений (инвестиций), в том числе отдельных этапов, планируемых на различных стадиях реализации инвестиционных проектов; оценка результатов деятельности объектов аудита инвестиционных проектов; оценка эффективности капитальных вложений (инвестиций) в инвестиционные проекты; оценка рисков недостижения целей, реализуемости инвестиционных проектов, включая риски потери вложенных федеральных и иных ресурсов.

Вместе с тем, несмотря на существование вышеуказанного стандарта, необходимо включить в область стратегического аудита государственные инвестиционные (приоритетные) проекты и разграничить предметность аудита государственных и международных инвестиционных проектов и стратегического аудита.

Кроме того, при проведении аудита инвестиционных проектов предлагается учитывать результаты стратегического аудита и соответственно внести соответствующие изменения в стандарт по аудиту государственных и международных инвестиционных проектов.

Таким образом, предлагается разработать «Стандарт внешнего государственного аудита (контроля). Стратегический аудит» и закрепить различные приемы его проведения, включая оценку соответствия целей инвестиционных проектов содержанию государственных стратегий, сущности государственной политики в сфе- 
ре социально-экономического развития и безопасности, с учетом осуществления такого аудита на всех стадиях реализации инвестиционных проектов.

Оценка соответствия целей должна включать: анализ документов, определяющих приоритетность и результативность инвестиционных проектов государственным программным документам; формулирование вывода о соответствии (несоответствии) целей инвестиционных проектов содержанию государственных стратегий.

Акцентируем внимание, что в рамках стратегического аудита целесообразно осуществлять оценку влияния институтов развития на достижение национальных целей, инвестиционный климат и инновационные процессы в экономике. Огромная роль в рамках инновационной инфраструктуры отводится институтам развития, которые стимулируют привлечение частных инвестиций, создают особые условия для формирования среды предпринимателей, функционирующих в приоритетных сферах экономической деятельности [5].

Итак, основными задачами стратегического аудита в рамках направления инновационная деятельность и институты развития, предлагается:

- разработка рекомендаций и предложений по совершенствованию механизмов государственной поддержки, направленных на проведение и внедрение научных разработок, системы управления рисками при расходах на НИОКТР с учетом их влияния на достижение национальной цели по ускорению технологического развития;

- разработка предложений по корректировке целей, задач, ожидаемых результатов, показателей (индикаторов) государственных программ, в том числе в целях приведения в соответствие с документами стратегического планирования, а также предложений по устранению рисков недостижения национальной цели по ускорению технологического развития и увеличению количества организаций, осуществляющих технологические инновации;

- рекомендации госкорпорациям и ключевым организациям приоритетных отраслей промышленности, атомного энергопромышленного комплекса, космической отрасли по совершенствованию процесса разработки и исполнению ключевых программных документов (включая стратегии развития, программы инновационного развития и иные) в целях минимизации рисков недостижения прорывного научно-технологического развития и соответствующих осуществляющих технологические инновации, обеспечение ускоренного внедрения цифровых технологий в экономике и социальной сфере, создание в базовых отраслях экономики высокопроизводительного сектора, развивающегося на основе современных технологий и обеспеченного высококвалифицированными кадрами.

Таким образом, присутствует необходимость разработки методической базы, организационного, информационного и ресурсного обеспечения стратегического аудита. И здесь же важно подчеркнуть, что необходимо разработать усовершенствованную базу индикаторов развития и источников экономического роста под стратегический аудит.

В рамках совершенствования института государственного аудита, представляется обоснованным формирование системного подхода на базе комплексной системы, включающей в себя применение финансового аудита, аудита эффективности и стратегического аудита, которая позволяла бы органам внешнего контроля охватить весь цикл использования государственных средств: от разработки проекта до получения конечного результата. При этом важно выстроить выбор объектов, отталкиваясь от стратегического аудита, следуя финансовому, а затем аудиту эффективности. Необходима единая система сквозного контроля (или системного аудита) за реализацией приоритетных государственных проектов.

Кроме того, в реализации национальных проектов участвуют различные экономические субъекты, и успешное развитие каждого из них будет влиять на реализуемость национального проекта в целом. В этой связи, возникает необходимость использования стратегического аудита и на микроуровне.

Разработка и внедрение новых технологий аудита позволит получить актуальную, стратегическую финансовую информацию о деятельности организации.

Первоочередной задачей становится необходимость, регулярно проводить стратегический аудит внешней и внутренней среды субъекта экономической деятельности. Целью стратегического аудита выступает оценка качества разработанных стратегий на предприятии и с уче- 
том их перспективы развития.

По мнению Марковой В.Д. стратегический аудит обеспечивает не только последующий контроль стратегии организации, а также рассматривается как элемент стратегии [6, с. 275]. Гуденица О.В., считает, что при проведении стратегического аудита аудитор оценивает результаты проведенного в коммерческой организации стратегического анализа, осуществленный стратегический выбор и реализацию стратегии, а также контроль за ее реализацией [7, c. 68].

По итогам анализа указанного термина можно выделить группы ученых: (Пискунов А.А., Маркова В.Д.) -характеризуют стратегический аудит как одно из направлений управленческого аудита, оценивающее перспективы развития организации; (Стрикленд А. Дж., Томпсон А.А. [8], Ансофф И. [9], Журавлев П.В., Одегов Ю.Г. [10], Емельянова И.Н. [11], Томас Л. Уилен, Хангер Дж. Дэвид [12], Богатая И.Н. [13], Шишов Л.В., Гуденица О.В. Алексеева И.В. [14]) - стратегический аудит как самостоятельную отрасль аудиторской деятельности, включающую оценку внутренних и внешних факторов.

Таким образом, стратегический аудит должен базироваться на определенной методике, позволяющей оценить ресурсную составляющую и результативность запланированных планов и стратегий. Область стратегического аудита шире, чем, например, финансового, так как информационной базой данного вида аудита является не только финансовая отчетность, информация, но и данные аналитического учета. Стратегический аудит можно представить как часть комплексного аудита, включающий проверку стратегических решений, бизнес - стратегии развития организации.

Немаловажное значение приобретает вопрос экономической безопасности в контексте раскрытия финансовой информации при проведении негосударственного аудита.

Одной из мер, направленной на решение данной проблемы является разработка проекта Федерального закона «О введении мер защиты национальной экономики Российской Федерации и ограничении деятельности юридических лиц и граждан стран-агрессоров на территории Российской Федерации» [15] (далее - законопроект).

Законопроектом вводится определение «страны-агрессора», устанавливается, что ино- странным юридическим и физическим лицам, зарегистрированным в «стране-агрессоре», а также российским юридическим лицам аффилированным или зависимым от таких иностранных лиц, запрещается осуществление на территории Российской Федерации деятельности по проведению аудита, предоставлению юридических и иных консультационных услуг.

Такие меры связаны в первую очередь с тем, что в настоящее время консалтинговая инфраструктура российского бизнеса монополизирована иностранцами. Особое внимание в законопроекте уделяется вопросам оказания поддержки российскому сегменту в сфере аудита.

Основной целью аудита финансовой отчетности является выражение мнения аудиторской организации о достоверности отчетности экономического субъекта. При этом мнение аудитора о достоверности бухгалтерской отчетности может способствовать большему доверию к этой отчетности со стороны заинтересованных пользователей. И наоборот, информация об организации может быть подвержена искажениям в силу ряда факторов, в частности применения оценочных значений и возможности неоднозначной интерпретации фактов хозяйственной жизни, пристрастности или даже умышленности ее составителей, либо использована в интересах сторонних организаций, в том числе иностранных.

В настоящее время на рынке аудиторских услуг наблюдаются тенденции, увеличивающие риски нанесения ущерба отечественному бизнесу. Так в сфере регулируемой Федеральным законом от 30.12.2008 г. N307-Ф3 «Об аудиторской деятельности» [16], существенно доминируют представители иностранных аудиторских организаций, так называемой «Большой четверки» («PricewaterhouseCoopers», «KPMG», «Ernst\&Young», «Deloitte\&Touche») и наблюдается тенденция роста присутствия указанных организаций на рынке аудиторских услуг. Иностранные аудиторские организации в настоящий момент проводят аудит большинства стратегических предприятий Российской Федерации, доступ к такой информации угрожает cmpameгическим интересам Российской Федерации.

Принятие предлагаемых законопроектом изменений в федеральное законодательство позволит обеспечить защиту стратегической информации отечественных предприятий, ор- 
ганизовать выполнение поручений Президента РФ и привлечении на выполнение заказов для государственных нужд предприятий малого и среднего бизнеса, которыми в основном и являются аудиторские организации.

Для реализации вышеизложенных задач законопроектом предлагаются изменения в федеральное законодательство, направленное на: 1) определение видов запретных для иностранцев услуг в сфере аудита, в частности: аудит для государственных компании, государственных унитарных предприятий, муниципальных унитарных предприятий, государственных корпораций, и т.д.; аудиторские задания в целях получения государственного финансирования или получения финансирования со стороны организаций, перечисленных выше; 2) введение ограничения на выдачу допуска к проведению работ, связанных с использованием сведений, составляющих государственную тайну; 3) введение нормативного определения аффилированных (взаимозависимых) лиц, для целей законопроекта.

Выводы:

С учетом вышесказанного следует отметить, что в целях развития цифровой экономики, обеспечения экономической безопасности необходима существенная трансформация института аудита (как государственного, так и негосударственного) с учетом изменений законодательной базы.

Очевидно, что оказывает существенное влияние развитие науки и техники на институт аудита. Тем самым происходит трансформация финансового аудита, аудита эффективности и др. видов государственного аудита путем использования информационно-технологических и программных инструментов анализа данных. Кроме того, при проведении государственного аудита уделяется внимание фактору повышения результативности достижения показателей ускоренного внедрения цифровых технологий в экономике и социальной сфере. Комплекс контрольных и экспертно-аналитических меропри- ятий по проведению государственного аудита национальных проектов (программ), направленных на обеспечение ускоренного внедрения цифровых технологий в экономике и социальной сфере. Здесь же планируется внедрение комплекса контрольных и экспертно-аналитических мероприятий по проведению аудита критичных государственных активов в области информационных и телекоммуникационных технологий (центры обработки данных, вычислительные комплексы, информационные системы) на всех стадиях жизненного цикла.

Актуальными направлениями в рамках развития института аудита (как государственного, так и негосударственного) будут ключевые разработки в таких сферах как технологии блокчейн, кибер-безопасность, анализ данных и т.д. В этой связи присутствует необходимость применения новых технологий (методик) в процессе проведения аудита, расширения сотрудничества, развития профессиональных стандартов, а также обмен лучшими практиками и опытом.

В целях совершенствования института аудита, а также достижения указанных результатов предлагается:

- увеличение доли стратегического аудита в мероприятиях Счетной палаты;

- разработка и внедрение новых методологических подходов к проведению мероприятий по стратегическому аудиту;

- совершенствование структуры результирующих документов по итогам проведения стратегического аудита, включая формат их размещения в информационных системах;

- повышение качества контрольных и экспертно-аналитических мероприятий за счет акцента на применении риск-ориентированного подхода, рекомендациях по совершенствованию системы внутреннего контроля объектов проверки;

- внедрение процесса системного аудита, базирующегося на определенной последовательности объектов проверки (стратегический аудит, финансовый аудит, аудит эффективности).

\section{Библиографический список}

1. «Основные направления деятельности Счетной палаты Российской Федерации на 2019-2021 годы» (утв. Коллегией Счетной палаты РФ 26.04.2019 N ОНД 2019-2021, протокол от 23.04.2019 N16K (1312)) // Документ опубликован не был.

2. Указ Президента РФ от 07.05.2018 N204 (ред. от 19.07.2018) «О национальных целях и стратегических задачах развития Российской Федерации на период до 2024 года» // СЗ РФ. 2018. N20. Ст. 2817. 
3. Федеральный закон от 28.06.2014 N172-Ф3 (ред. от 31.12.2017) «О стратегическом планировании в Российской Федерации» // С3 РФ. 2014. N26 (часть I). Ст. 3378.

4. «СГА 304. Стандарт внешнего государственного аудита (контроля). Аудит государственных и международных инвестиционных проектов» (утв. постановлением Коллегии Счетной палаты РФ от 23.12.2016 N8ПК) // Документ опубликован не был.

5. Терехова Е.В. Инновационная инфраструктура инвестиционной модели (финансовые, организационно-правовые, институциональные аспекты) // Вопросы экономики и права. № 2 (128). 2019. С. 61.

6. Маркова В.Д., Кузнецова С.А. Стратегический менеджмент. М.: ИНФРА-М, 2002. 288 с.

7. Гуденица О.В., Шишов Л.В. Стратегический аудит в коммерческих организациях. Ростов-на-Дону: БУПК. 2008. $148 \mathrm{c}$.

8. Томпсон А.А., Стрикленд А. Дж. Стратегический менеджмент. Искусство разработки и реализации стратегии. М.: Банки и биржи. ЮНИТИ, 1998. 345 с.

9. Ансофф И. Новая корпоративная стратегия. СПб.: Питер Ком, 1999. 258 с.

10. Одегов Ю.Г., Журавлев П.В. Управление персоналом. М.: Финстатинформ, 1997. 878 с.

11. Емельянова И.Н. Место стратегического аудита в системе стратегического планирования // Актуальные проблемы бухгалтерского учета, анализа, аудита, налогообложения и статистики. Всерос. науч.-практ. конф. Ростов н/Д: РИНХ, 2009. С. 191-194.

12. Хангер Д., Уилен Т. Основы стратегического менеджмента. М.: ЮНИТИ-ДАНА, 2008. 287 с.

13. Богатая И.Н. Стратегический учет и аудит: теория и практика // Фундаментальные исследования. 2007. № 4. С. $87-90$.

14. Алексеева, И.В. Стратегический аудит как перспективное направления направление развитие аудита / И.В. Алексеева // Учет и статистика. 2008. № 2 (12).

15. Постановление ГД ФС РФ от 09.06.2015 N6820-6 ГД «О проекте Федерального закона N667782-6 «O введении мер защиты национальной экономики Российской Федерации и ограничении деятельности юридических лиц и граждан стран агрессоров на территории Российской Федерации» // С3 РФ. 2015. N25. Ст. 3549.

16. Федеральный закон от 30.12.2008 N307-Ф3 (ред. от 23.04.2018) «Об аудиторской деятельности» // СЗ РФ. 2009. N1. Ст. 15. 